\title{
O desenvolvimento do ecoturismo na Praia da Barrinha na Ilha das Canárias (MA)
}

\author{
The ecotourism development on the Barrinha Beach, \\ Ilha das Canárias (MA, Brazil)
}

\author{
Mayara Maia Ibiapina
}

\section{RESUMO}

Apesar do ecoturismo ser caracterizado incialmente pelo contato com áreas naturais, é preciso entender seu real significado, sua atuação deve estar ligada a uma relação entre interpretação, conservação e sustentabilidade, incentivando o turismo consciente e disseminando o conhecimento sobre a natureza. Dentro dessa perspectiva o presente estudo buscou reunir informações sobre a Praia da Barrinha na llha das Canárias MA, investigando as possibilidades para o desenvolvimento do ecoturismo nessa área. A metodologia utilizada foi a etnoecologia ou etnoconhecimento, que utiliza o conhecimento dos autóctones para encontrar possíveis atrativos na praia. A pesquisa tem caráter qualitativo e exploratório, utiliza a aplicação da metodologia conhecida como bola de neve ou snowball para definir a amostra que participou das entrevistas estruturadas que fundamentaram a formação de um diagnóstico sobre a região. Além disso, foram feitas pesquisas de campo para a realização de fotografias que foram indispensáveis para a formação de um inventário preliminar de atrativos ecológicos da praia. Dessa forma a criação de um diagnóstico do local revelou que apesar da área dispor de muitos atrativos ecológicos ela possui pouca visitação, as pessoas que frequentam a praia são na maioria pescadores provenientes das comunidades próximas, ela apresenta ainda um ambiente ecologicamente sensível que necessita de planejamento e utilizando as diretrizes das práticas de turismo sustentável podendo subsidiar futuros estudos de planejamento, uso e manejo da Praia de Barrinha MA, pois o ecoturismo tem capacidade de trazer benefícios sociais e ambientais e ainda ser perfeitamente rentável.

PALAVRAS-CHAVE: Ecoturismo; Etnoconhecimento; Praia da Barrinha. 


\section{ABSTRACT}

Althoug ecotourism be characterized initially by contact with natural áreas it must be understood, conservation anda sustainability, encouraging the tourism conscious and disseminating knowledge about nature. Within this perspective, the presente study seeks to gather information on the Barrinha Beach in the llha das Canárias (MA, Brazil), investigating the possibilities for the development of ecoturismo in this área, but few bibliographic information was found from the beach . the methodology used was ethnoecology_ethnic knowledge, using the knowledge of indigenous possible to find attractive on the beach. The quantitative research is exploratory and uses the application of the methodology know as snowball to set the sample whoparticipated in structured interviews, which supported the formation of a diagnosis of the region. In addition, field surveys were make, for holding photopraphs that were indispensable for the formation of a preliminary inventory of ecologial attractions of the beach. Thus the establishment of a diagnosis of the local revealed that although the area have many ecological attractions in has little visitation. People who frequent the beach are mostly fishermen from the nearby communities, it also presents an ecologically sensitive environment which requires planning and using the guidelines of sustainable tourism practices can facilitate future studies of planning, use and management of Praia da Barrinha MA because ecotourism has the capacity to bring social and environmental benefits and still be perfectly profitable.

KEYWORDS: Ecotourism; Ethnoecology; Barrinha Beach.

\section{Introdução}

O turismo é uma atividade ainda emergente mas que apresenta elevados índices de crescimento, a previsão segundo a Organização Mundial do Turismo (2014) é que ao longo das décadas o turismo se torne o setor econômico com o maior crescimento do mundo, isso implica um número crescente de novos destinos, o que torna o turismo um fator chave para o progresso socioeconômico, hoje, o volume de negócios movimentados pelo turismo iguala ou até supera o das exportações de petróleo, produtos alimentares ou de automóveis (OMT, 2014). No Brasil, o setor tem se fortalecido e existe um crescimento tanto do turismo internacional quanto ao turismo doméstico, atraídos especialmente pelas belezas naturais (MTUR, 2014).

As viagens oferecem contato com outras culturas e ambientes, trazendo aos indivíduos experiências de interação com outras pessoas e com o meio que os cerca, essas viagens têm origens muito antigas, mas o turismo moderno tem sua origem após a Revolução Industrial, hoje ele é considerado uma atividade socioeconômica que gera bens e serviços.

Para Molina (2001), o turismo transformou-se em uma atividade econômica de grande importância no planeta observando-se os números de deslocamentos, os empregos gerados, o seu impacto na Balança de Pagamentos, no Produto Nacional, bem como o montante de investimentos e gastos públicos ou privados que propicia além da possibilidade de 
desenvolvimento das comunidades e dos indivíduos, assim, existe uma ligação entre turismo e ecologia, uma vez que o processo de globalização pode levar os turistas a procurar novos destinos com maior qualidade ambiental ele defende a formação de uma consciência ambiental na sociedade, que estimulou o nascimento de novas gerações de visitantes, que ele chama de "novo turista", que passa de um turista poluidor a um turista mais consciente.

Nesse contexto, a globalização e o surgimento de um "novo turista" fazem exigências quanto a qualidade ambiental tanto dos destinos já conhecidos, quanto dos novos destinos, esse relacionamento próximo do turismo e ecologia apresenta o ecoturismo como uma alternativa de desenvolvimento que possibilite o desenvolvimento econômico e ao mesmo tempo consiga mantes a biodiversidade e estabilidade do meio ambiente.

Apesar do poder transformador do turismo, entende-se que o atual sistema econômico tem reafirmado exploração dos recursos naturais disponíveis, causando degradação ambiental e desigualdade social, questiona-se então, o verdadeiro conceito de ecoturismo. Wearing e Neil (2001) apontam o ecoturismo como um conceito complexo e contraditório que entrou em moda após a década de 1990 com o declínio dos movimentos ambientalistas, e para que esse título não seja usado apenas para atrair clientes e não desempenhar seu papel de sustentabilidade é necessário planejamento.

Muitas vezes o conceito de ecoturismo é confundido e tratado apenas como a visitação em áreas naturais, porém muitos autores defendem que o ecoturismo deve ser uma forma de utilizar o patrimônio natural e cultural de forma sustentável e observando as questões sociais.

Ecoturismo é o segmento da atividade turística que utiliza, de forma sustentável, o patrimônio natural e cultural, incentiva sua conservação e busca a formação de uma consciência ambientalista por meio da interpretação do ambiente, promovendo o bem-estar das populações (Marcos Conceituais - MTur)

Muitas vezes o conceito de ecoturismo é confundido e tratado apenas como um turismo que ocorre em áreas naturais, porém o ecoturismo é um dos segmentos do turismo, onde se deve utilizar o patrimônio natural e cultural de forma sustentável, esse segmento incentiva a conservação das áreas visitadas e busca a formação de uma consciência ambientalista por meio da interpretação do ambiente o que promove o bem-estar das populações.

Com isso, apesar do ecoturismo ser caracterizado inicialmente pelo contato com áreas naturais, é preciso entender seu real significado, pois sua atuação deve estar ligada a uma relação entre interpretação, conservação e sustentabilidade, incentivando o turismo consciente e disseminando o conhecimento sobre a natureza. Dentro dessa perspectiva precisamos conhecer a área e investigar suas possibilidades para resolver o seguinte 
questionamento: quais as possibilidades para o desenvolvimento na Praia da Barrinha na llha das Canárias (MA)?

Dessa forma o presente trabalho investiga atrativos que possibilitem o desenvolvimento do ecoturismo na região pela localização geográfica privilegiada, visto que a Praia da Barrinha se encontra dentro de duas unidades de conservação ambientais sobrepostas, são elas a Área de Proteção Ambiental Delta do Parnaíba e a Reserva Extrativista Delta do Parnaíba.

Pela falta de registros sobre o local, o presente trabalho faz estudos preliminares realizados em visitas realizadas ao local objeto de estudo que revelam um rico ambiente natural com forte presença de pescadores e uma paisagem atrativa a visitantes, a presença desses pescadores, guias de turismo ou apenas visitantes vão embasar as pesquisas na busca dos atrativos.

O conhecimento caiçara pode ser o ponto de partida para novos planos de gestão ambiental que visem conservar tanto a biodiversidade quanto as diferentes culturas brasileiras. Muitos estudos têm sido desenvolvidos nesta área temática, enfocando as relações entre as comunidades tradicionais e os recursos naturais do ambiente (SOUZA, 2004, p. 23).

Assim, para explorar o local serão utilizadas as informações dos autóctones da região do Delta do Parnaíba, esses moradores da área de entorno da Praia da Barrinha ou pessoas que de alguma forma se relacionam com ela, seja com o trabalho ou lazer, possuem um conhecimento da área que é de grande importância para esse estudo inicial, trata-se do etnoconhecimento, um instrumento capaz de nos levar a identificar de forma mais eficiente os possíveis atrativos locais.

Nesse contexto, a Praia da Barrinha na Ilha das Canárias, Maranhão, foi identificada pelo Instituto Tartarugas do Delta - ITD, através do Projeto Biodiversidade Marinha do Delta - Biomade, como uma área de grande importância para a região do Delta do Rio Parnaíba pela particularidade da área tanto ser um local para alimentação, refúgio e descanso de animais como também ser utilizada por pescadores da região.

O TID é uma instituição sem fins lucrativos que desenvolve trabalhos de conservação na região há oito anos, atualmente está executando o projeto Biomade patrocinado pela Petrobras através do Programa Petrobras Socioambiental. As ações de conservação são trabalhadas através da pesquisa, educação ambiental e geração de renda. Para Pires (2002, p. 73), "as ONGs são fundamentais no resguardo da aplicação de princípios éticos nos projetos e ações empreendidos pela sociedade em nome do ecoturismo".

Assim o objetivo da pesquisa foi investigar possibilidades para 0 desenvolvimento do ecoturismo na Praia de Barrinha na Ilha das Canárias MA, realizando um diagnóstico do perfil ambiental da Praia da Barrinha e um 
inventário preliminar dos atrativos e potencialidades para o desenvolvimento do ecoturismo através do etinoconhecimento para apresentar alternativas mais sustentáveis através do ecoturismo e suas vertentes.

\section{Meio Ambiente e turismo}

Os movimentos sociais e ecológicos surgiram na década de 1960 e questionava o preço pago pelo desenvolvimento dos países capitalistas, o movimento ecológico em particular, questionava o modo de produção e de vida em que estavam se organizando as sociedades modernas (GONÇALVES, 2014, p.11), nesse período já existiam alarmes sobre a destruição de áreas naturais e divulgação de descobertas da importância da biodiversidade para a medicina e outras áreas.

Pires (2002), esclarece que foi a partir dessa década de 1970 que começam a acontecer eventos como seminários e encontros nacionais onde já iniciam uma discussão acerca dos impactos socioeconômicos, culturais e ambientais do turismo e foi na conferência da OMT de 1980, em Marília que iniciou-se uma reflexão para dentro do turismo com relação ao momento de mudança de mentalidade em relação à sociedade e ao modelo de desenvolvimento, nela surgiram propostas para um "turismo alternativo" onde existiria uma preocupação com a melhora da qualidade de vida das populações.

Em meio a essa inserção das populações nas questões ambientais surge em 1987 o Relatório de Brurntland pela Comissão de Meio Ambiente e Desenvolvimento das Nações Unidas, também conhecido como "Nosso futuro comum", esse relatório introduziu conceitos de "conservação" e "desenvolvimento sustentável" derrubando o ideal preservacionista dos ambientalistas, para Wearing e Neil (2001), foi sem dúvidas um grande avanço mundial da consciência ambiental, esse relatório destacava um grande dilema ao qual faz refletir até os dias atuais, tem-se um mundo com mais de cinco bilhões de pessoas, é possível suprir todas as necessidades dessas pessoas, sem destruir o planeta, bem como a própria vida humana.

No Brasil, a ideia de unir turismo e ecologia emerge na década de 90 principalmente através da preocupação com a manutenção da paisagem. As principais contribuições acadêmicas surgiram após a realização da ECO-92 no Rio de Janeiro onde iniciaram-se as produções científicas em torno do Ecoturismo, Pires (2002) ainda considera uma falta de contextualização histórica capaz de localizar o ecoturismo no tempo e no espaço, o que permitiria o reconhecimento da sua contemporaneidade e questionava também a abrangência e aprofundamento dos estudos. Para o autor esses estudos ainda revelavam um quadro embrionário de produção científica, apesar disso, o século XX viveu uma evolução do ecoturismo e significativas mudanças das visitas às áreas naturais associados a essa nova necessidade de conservar os ecossistemas através do desenvolvimento sustentável.

Um ecossistema, "é composto por um meio abiótico ou não-vivo (fatores climáticos, químicos), [...] e um meio biótico ou seres vivos (plantas, 
animais, aves)" (MOLINA, 2001, p.101), esse sistema e suas trocas de energia precisam ser consideradas no planejamento sobre quaisquer atividades realizadas em seu meio para entender seus limites.

Os ecossistemas naturais devem desenvolver uma gestão que, se for interrompida pelo homem, causará grandes desequilíbrios nos próprios ecossistemas, com projeções além de seus próprios limites. Os seres humanos desconheceram por muito tempo os sistemas ecológicos, e agora é o momento de estudá-los a fundo, relacionando-os, desse modo, às atividades que neles se desenvolvem (MOLINA, 2001, p.105).

Dessa forma, o que se percebe na atualidade é que a escassez de alguns recursos naturais como a água, a alteração climática e os desastres ambientais têm provocado uma consciência diferente na sociedade. Para Molina (2001), o maior problema enfrentado hoje pela humanidade é a poluição do meio natural, as consequências mais graves disso são a perda dos recursos naturais que necessários para sustentar a vida no planeta e os efeitos nocivos sobre a saúde humana.

As causas são geralmente atribuídas ao crescimento populacional e ao uso de certas tecnologias que degradam o meio, pois não foram observados estudos prévios de impactos ambientais, então, a necessidade de conciliar a conservação dos recursos naturais com o desenvolvimento às populações torna o ecoturismo uma atividade importante para áreas naturais, pois o turismo convencional, demanda uma transformação radical dos ecossistemas e um grande consumo de recursos naturais. Segundo Molina, a definição de Ecologia é:

\footnotetext{
Etimologicamente, a palavra ecologia deriva dos termos gregos oikos (casa) e logos (estudos de), que em conjunto querem dizer "estudo da casa", e por extensão, "estudo do meio ambiente". O conceito moderno de ecologia nos assinala que é a ciência que estuda as características, significado e a magnitude das relações entre os seres vivos e o meio ambiente não-vivo. Muitos pesquisadores dizem que a ecologia é o estudo "da estrutura e função da natureza”. (MOLINA, 2001, p.99).
}

Assim, a ecologia estuda os efeitos dessa poluição sobre os ecossistemas, porém, as questões ambientais implicam a intervenção de várias áreas do conhecimento, de forma interdisciplinar e transdisciplinar, são necessárias outras áreas e tecnologias, por isso, o planejamento e administração da atividade turística deve se integrar a conservação desses ecossistemas, a atividade turística está ligada ao uso dos recursos naturais e sua conservação para garantia de sustentabilidade do turismo. 
Portanto, "Turismo e meio ambiente são realidades inseparáveis" (CORIOLANO, 2007, P.19). Segundo Archer e Cooper (2001, p.102) "A cuidadosa formulação da política e um planejamento criterioso podem contribuir bastante para minimizar ou até eliminar os efeitos negativos", os autores atribuem ao turismo uma capacidade de contribuir com a qualidade social, cultural, ambiental e econômica de um país, mas para isso precisa-se de políticos, planejadores e empreendedores dispostos visualizar essa oportunidade.

\section{A construção do conceito ecoturismo}

O crescimento da atividade turística desperta uma série de preocupações, por isso, são recorrentes as discussões a respeito dos impactos causados pela atividade, principalmente pelo turismo de massa, que se configura inicialmente pelo deslocamento de um grande número de pessoas o que segundo Ruschmann (1999, p 23), trazem grandes problemas como a sazonalidade e "tem contribuído para agressões socioculturais nas comunidades receptoras e para a origem de danos, às vezes irreversíveis, nos recursos naturais".

Buscou-se uma forma de "turismo alternativo" ao turismo convencional, esse turismo alternativo tinha que se apresentar de uma forma menos impactante, na opinião de Wearing e Neil (2001, p.4) em um sentido mais amplo, pode-se entender por essa forma de turismo como aqueles que "demonstram ser coerentes com os valores natural, social e comunitário e que permitem que tanto hospedeiros quanto hóspedes desfrutem uma interação positiva e conveniente, e compartilhem experiências".

Porém, para Macleod (2001, p.179), apesar do consenso a respeito do significado do termo Turismo alternativo, "as fronteiras entre o turismo de massa e o turismo alternativo estão desaparecendo", utilizando-se da argumentação que surgem frequentemente várias formas de turismo diminuindo a fronteira entre elas. Como o exemplo de uma excursão que viaja em grandes grupos, porém que possui pensamento diferenciado, preferindo visitar lugares exóticos, vivenciando a cultura local, dispostos a aprender e causar menor impacto possível nessa localidade, observa-se nesse exemplo um turismo de massa com características alternativas.

Assim, na busca de entender melhor o fenômeno turístico, aos poucos surgem várias formas de turismo alternativos como o turismo cultural, turismo educacional, turismo científico, turismo de aventura, agroturismo e várias outras segmentações que são classificadas a partir da principal motivação do visitante, e dentro dessa perspectiva, surge o ecoturismo, como uma forma de turismo alternativo baseado na natureza.

Durante muito tempo discutiu-se uma definição para ecoturimo. "Em termos gerais, entende-se que é um turismo que tem lugar em ecossistemas, em ambientes naturais, e, por outro lado, que busca favorecer o conhecimento e aprendizado de manifestações naturais, mediante certas interações de baixo impacto" (MOLLINA, 2001, p.159). E num contexto brasileiro o Grupo de Trabalho Interministerial em Ecoturismo composto pelo 
pelo Ministério da Indústria, comércio e Turismo, Ministério do Meio Ambiente, Embratur, Ibama, empresários e consultores definem que o ecoturismo como um segmento que que "utiliza, de forma sustentável, o patrimônio natural e cultural, incentiva sua conservação e busca a formação de uma consciência ambientalista através da interpretação do ambiente, promovendo o bem-estar das populações envolvidas" (BRASÍLIA: Embratur/lbama, 1994 apud PIRES, 2002, p.151).

O termo apareceu escrito pela primeira vez na edição de março/abril de 1984 da Américan Birdes, como propaganda para uma atividade turística dirigida por Ceballos-Lascurain. A definição do termo como a conhecemos apareceu pela primeira vez em 1987, em um documento intitulado "O futuro do ecoturismo" que foi reproduzido no Mexico Journal, na edição de 27 de janeiro de 1988 (WEARING E NEIL, 2001, p.6)

Desta forma, apesar do termo ecoturismo ter sido usado pela primeira vez em 1984, ele efetivamente veio consagrar-se a partir da década de 90 , quando o termo "turismo ecológico", como era antes designado o novo segmento que surgia, começou a ser incorporado de novas abordagens teóricas e acabou entrando em desuso, dessa forma, o termo "turismo ecológico" e "ecoturismo" podem ser usados como sinônimos apesar de que falando do ponto de vista da contemporaneidade a primeira forma já não é considerada a forma mais adequada (PIRES, 2002, p.125).

O Ambientalismo e as idéias ecológicas serviram de bases iniciais para o surgimento do ecoturismo, e trazem a ideia de que o turismo realizado na natureza pode ser uma oportunidade de trazer benefícios sociais e ambientais e ainda ser perfeitamente rentável.

O Ecoturismo não pode ser considerado uma atividade ideal, não impactante e não poluente, mas se comparado à outras atividades é menos doloso. Entretanto, pode ser praticado de maneira racional, duradoura e capaz de melhorar a qualidade de vida de uma grande parcela da população. É o Ecoturismo responsável, que se aproxima da sustentabilidade, visando a conservação do patrimônio natural e cultural, desenvolvendo atividades lucrativas que possam garantir a sua manutenção e a melhoria de vida das comunidades envolvidas (CORREIA, 2003, p. 7).

Com isso, o ecoturismo se defronta com 0 desafio do desenvolvimento sustentável, para o Fundo Mundial para a Natureza (WWF) esse desenvolvimento sustentável é "capaz de suprir as necessidades da geração atual, sem comprometer a capacidade de atender as necessidades das futuras gerações. É o desenvolvimento que não esgota os recursos para o futuro", trata-se de uma forma desenvolvimento que se preocupa com a 
manutenção dos recursos pois entende-se que deles dependem a vida humana no planeta. Assim, para obter o desenvolvimento é preciso que o lugar obtenha um crescimento econômico alinhados com o princípio da igualdade e justiça social, mas também observando as questões ambientais.

Entende-se a dificuldade de conciliar a atividade econômica com a conservação dos ambientes, por isso, é preciso relembrar que o desenvolvimento do ecoturismo deve considerar alguns aspectos como:

\begin{abstract}
Promover e desenvolver o turismo, em bases cultural e ecologicamente sustentáveis; promover e incentivar investimentos em conservação dos recursos naturais e culturais utilizados; fazer com que a conservação beneficie, materialmente, comunidades envolvidas, pois, somente servindo de fonte de renda alternativa, estas se tornarão aliadas de ações conservadoristas; ser operado de acordo com critérios de mínimo impacto, de modo a ser uma ferramenta de proteção e conservação ambiental e cultural; e educar e motivar as pessoas para que percebam a importância de se conservar a cultura e a natureza (BNDES, 2000, p. 1).
\end{abstract}

Para Zacchi (2004) a democratização das informações e o conhecimento sobre as novas questões sobre a vida no planeta influenciaram o surgimento do novo turista e destaca em seus estudos sobre a conceitualização do ecoturismo as diferenças entre o turista tradicional e esse novo turista.

Turistas Tradicionais: procura a imitação artificial cuja experiência the propicie o fantástico e o sonho para satisfação de todas as suas necessidades e onde a semelhança opõe-se a identidade. Geralmente compõem um estrato social de altíssimo nível não valorizando a experiência e a emoção captado no aprendizado das relações. Padronizam a população como seres primitivos e atrasados. Invariavelmente permanecem em complexos e resorts, verdadeiros guetos turísticos na visão de Kripendorff (1989), percebendo tudo do "alto para baixo". Não importa os aspectos verdadeiros de uma região, mas sim a imagem que existe nele mesmo. Este tipo é altamente prejudicial, pois para o estabelecimento da atividade, seus atores se valem da visão messiânica do turismo.

Novo Turista: procura a autenticidade da destinação, busca principalmente os ecossistemas mais tradicionais da comunidade autóctone. Visitam os ícones turísticos do local, mas fundamentalmente escolhem ambientes onde os guias não levam, atribuindo-Ihes valores excepcionais. Procuram sair do comum e buscam vivenciar as práticas locais. Também são turistas de alto poder aquisitivo, experientes e altamente exigentes. Diferentemente dos turistas 
tradicionais, o Novo Turista preocupa-se com o mix do produto, seu desempenho e relação, impondo naturalmente um posicionamento ecocêntrico. Transformam o núcleo receptivo, sua estada por assim dizer, numa sala de aula, num laboratório vivo identificando todos os detalhes peculiares dos anfitriões. Respeitam a fragilidade da terra e a dignidade alheia. São consumidores conscientes com forte orientação para preservação (ZACCHI, 2002, p.103 apud ZACCHI, 2004, p.8)

Dessa forma, entende-se que o surgimento de um novo turista, mais consciente e exigente, é um passo importante para o surgimento de novos produtos turísticos mais preocupados com as questões ambientais e com isso a própria manutenção do turismo, porém, para desenvolver o ecoturismo de forma ecologicamente equilibrada, são necessárias ações conjuntas das diversas partes envolvidas: órgãos públicos, privados, não governamentais e a comunidade, insistindo no planejamento, pesquisas e discussões.

\section{Destinos e boas práticas em ecoturismo}

Um dos pioneiros em na área de conservação da natureza, que criou a primeira unidade de conservação do mundo, o Parque Nacional de Yellowstone em 1872 os Estados Unidos da América é o país que apresenta o maior mercado de ecoturismo no mundo. Para isso o país utiliza especialmente os parques nacionais e os turistas domésticos. Em 2007, de acordo com o órgão responsável pela administração das Unidades de Conservação Federais Norte Americanas, os Parques Nacionais receberam mais de 62 milhões de visitantes, de um total de 275.581 .547 visitas em Ucs, outros destinos importantes do país são o Grand Canyon, o Alasca e o Havaí (SÃO PAULO, 2010, p. 60).

Outro exemplo que se destaca em ecoturismo na atualidade é um destino já conhecido pelos brasileiros, porém pouco conhecido em outros locais, a Nova Zelândia, algumas atividades famosas são o mergulho no Parque Marinho de Poor Knights, caminhadas no Parque Nacional de Tongariro e escalada no Monte Cook, seu parque nacional mais conhecido chama-se Fiordland. De acordo com o Departamento de Conservação neozelandês, o país recebeu em 2006, 2.223.500 milhões turistas, sendo que deste total 668.400 visitaram algum Parque Nacional (Ibden, 2010, p. $61)$.

Já a Costa Rica é reconhecida em todo o mundo pelas suas ações em torno da conservação ambiental, o país tem cerca de um quarto do território do país dentro de Unidades de Conservação com um total de 160 áreas protegidas, das quais apenas 32 recebem visitantes. De acordo com o Instituto Costaricense de Turismo, em 2005, o país recebeu 1.679.051 turistas internacionais atraídos principalmente pelo ecoturismo (Ibden, 2010, p. 61).

Um grande exemplo de estratégias em ecoturismo foi o Quênia, onde o turismo é a principal atividade econômica responsável por $10 \%$ do PIB, o 
país desenvolveu um modelo de valoração sobre a atração turística dos animais, é o principal destino africano para a prática dos safáris, além de utilizar-se bem de sua diversidade de ecossistemas como glaciais, desertos áridos, cadeias montanhosas, savanas, florestas tropicais e praias. De acordo com o "Kenya National Bureau of Statistics" os parques e reservas do Quênia receberam mais de 2,3 milhões de visitantes no ano de 2006, incluindo quenianos e estrangeiros (Ibden, 2010, p. 60).

O Perú também é destaque em ecoturismo no cenário internacional, de acordo com as publicações do Banco Nacional de Desenvolvimento (BNDES):

Peru - maior concorrente do Brasil, na disputa pelo mercado de ecoturistas. Possui boa infra-estrutura, confortáveis hotéis de selva, parques administrados por pessoal bem treinado, ingressos com custos reduzidos, e tarifas aéreas também baratas, situação esta radicalmente oposta à do Brasil (BNDES, 2000, p. 4).

No Brasil encontramos grande potencial ecoturístico, pois é "um dos países com maior biodiversidade pela riqueza de seus biomas (Amazônia, Mata Atlântica, Campos Sulinos, Caatinga, Cerrado, Pantanal e Zona Costeira e Marítima) e seus diversos ecossistemas" (BRASIL, 2001), apesar de ainda não apresentar infraestrutura adequada e planejamentos de conservação e manejo necessários para a manutenção da atividade ele também possui bons exemplos em ecoturismo a serem observados.

Um bom exemplo a ser comentado é a Amazônia, que embora seja o destino ecoturístico brasileiro mais conhecido do mundo, ainda não recebe um número expressivo de visitantes. Em 2005, a Amazônia brasileira foi responsável por apenas 0,05\% (400 mil turistas) do total de chegadas internacionais no mundo. Entre os notáveis atrativos da Amazônia estão os Rios Negro e Solimões, o Monte Roraima, a Serra do Divisor e o Pico da Neblina. (SÃO PAULO, 2010, p. 56)

Outra região bastante propícia ao ecoturismo é o Pantanal, uma das maiores áreas alagáveis do planeta, foi reconhecida pela Organização das Nações Unidas para a Educação, a Ciência e a Cultura (UNESCO), no ano 2000, como Patrimônio Natural Mundial e Reserva da Biosfera. A região abriga uma das maiores biodiversidades do globo. De acordo com a WWF existem 656 espécies de aves no Pantanal, mais do que na América do Norte inteira. Atividades de pesca e fotografia de aves tornam alguns destinos importantes como sua porção sul, os municípios de Miranda, Aquidauana e Corumbá e, na região norte, Poconé, Cáceres e Barão de Melgaço e Bonito, com destaque para este último pois trata-se de um destino premiado em ecoturismo e conservação ambiental (Ibden, 2010, p. 56).

O arquipélago de Fernando de Noronha trata-se de uma região com cerca de $26 \mathrm{~km}^{2}$ constituída por 21 ilhas, rochedos e ilhotas. Devido a qualidade de suas paisagens, sua situação geográfica privilegiada e existência de espécies endêmicas (que só ocorrem no arquipélago), foi criado o Parque Nacional Marinho de Fernando de Noronha em 1988. Esse 
caso merece uma atenção especial pelo seu exemplo em planejamento pois, além de possuir um limite diário de visitantes observando sua capacidade de suporte de visitas ele adota práticas sustentáveis que induz aos visitantes seguirem práticas ambientais mais conscientes e responsáveis (Ibden, 2010, p. 57).

Outro local muito admirado é o Parque Nacional do Iguaçu, o mais visitado do Brasil e melhor sucedido também em concessões de empresas privadas como o Hotel Cataratas, o Centro de Visitantes e o Macuco Safári. Nele estão as cataratas mais belas do planeta reconhecidas em 1986 como Patrimônio Natural da Humanidade pela UNESCO. Em 2007 o parque recebeu 1.055 .433 visitantes, sendo que cerca de $57 \%$ eram estrangeiros de acordo com dados do ICMBio e o número de visitantes do parque continua crescendo em um ritmo acelerado (Ibden, 2010, p. 57).

E por fim menciona-se o município de Brotas, onde seu principal atrativo é o Rio Jacaré Pepira, excelente local para a prática do rafting, da canoagem e de outros esportes de aventura. As propriedades particulares controlam os impactos de visitação e garantem a qualidade da experiência do turista, a prefeitura criou o Sistema Municipal de Controle da Visitação Turística (Ibden, 2010, p. 59).

\section{Áreas Protegidas}

Para garantir a proteção legal de áreas naturais pelo poder público no Brasil foram criadas as unidades de conservação (UCs) que atualmente são regulamentadas através da Lei No 9.985, DE 18 DE JULHO DE 2000 pelo Sistema Nacional de Unidades de Conservação da Natureza (SNUC). O Art. $4^{\circ}$ do SNUC estabelece os seguintes objetivos:

I - contribuir para a manutenção da diversidade biológica e dos recursos genéticos no território nacional e nas águas jurisdicionais;

II - proteger as espécies ameaçadas de extinção no âmbito regional e nacional;

III - contribuir para a preservação e a restauração da diversidade de ecossistemas naturais;

IV - promover o desenvolvimento sustentável a partir dos recursos naturais;

V - promover a utilização dos princípios e práticas de conservação da natureza no processo de desenvolvimento; $\mathrm{VI}$ - proteger paisagens naturais e pouco alteradas de notável beleza cênica;

VII - proteger as características relevantes de natureza geológica, geomorfológica, espeleológica, arqueológica, paleontológica e cultural;

VIII - proteger e recuperar recursos hídricos e edáficos;

IX - recuperar ou restaurar ecossistemas degradados;

$X$ - proporcionar meios e incentivos para atividades de pesquisa científica, estudos e monitoramento ambiental;

XI - valorizar econômica e socialmente a diversidade biológica; 
XII - favorecer condições e promover a educação e interpretação ambiental, a recreação em contato com a natureza e o turismo ecológico;

XIII - proteger os recursos naturais necessários à subsistência de populações tradicionais, respeitando e valorizando seu conhecimento e sua cultura e promovendo-as social e economicamente (BRASIL, 2000, Art 5).

O SNUC é responsável pela proteção de cerca de 1,5 milhão de quilômetros quadrados do território brasileiro e integrando áreas protegidas federais, estaduais, municipais e particulares, por isso a gestão dessas áreas representa um grande desafio. As UCs, em resumo, buscam gerar benefícios a sociedade, protegendo mananciais de água, ajudando a regular - clima, contendo erosões, oferecendo oportunidades de lazer com apreciação de paisagens únicas, mantendo riquezas culturais e trazendo alternativas econômicas sustentáveis de desenvolvimento e são administradas pelo Instituto Chico Mendes de Conservação da Biodiversidade (ICMBio).

O ICMBio é uma autarquia em regime especial, criada dia 28 de agosto de 2007, pela Lei 11.516, e está vinculada ao Ministério do Meio Ambiente integrando o Sistema Nacional do Meio Ambiente (Sisnama). A principal atribuição do instituto é executar as ações do SNUC, podendo propor, implantar, gerir, proteger, fiscalizar e monitorar as Ucs além de incentivar e executar programas de pesquisa, proteção, preservação e conservação da biodiversidade e exercer o poder de polícia ambiental para a proteção das Unidades de Conservação federais (ICMBio, 2015)

Para isso, as UCs foram divididas em duas categorias: Proteção Integral e Uso Sustentável. São Unidades de Proteção Integral as Estações Ecológicas, as Reservas Biológicas, os Parques Nacionais, os Monumentos Naturais e as áreas de Refúgio de Vida Silvestre. São Unidades de Uso Sustentável as Áreas de Proteção Ambiental, as Áreas de Relevante Interesse Ecológico, as Florestas Nacionais, as Reservas Extrativistas, as Reservas de Faunas, as Reservas de Desenvolvimento Sustentável e as Reservas Particulares do Patrimônio Natural.

O presente trabalho trata de uma área que está localizada dentro de duas categorias de UCs sobrepostas, uma Area de Proteção Ambiental (APA) e uma Reserva Extrativista (RESEX), que apresentam uma forma mais flexível de visitação. O Art. $15^{\circ}$ do SNUC (2001) expressa que a APA geralmente é uma área extensa, onde seus atributos abióticos, bióticos, estéticos ou culturais são de grande importância para a qualidade de vida não só da população residente como todas as populações humanas, seu primeiro objetivo é proteger a diversidade biológica e controlar a ocupação e o uso dos recursos, as características mais específicas do mesmo parágrafo especificam que:

§ 10 A Área de Proteção Ambiental é constituída por terras públicas ou privadas.

$\S 20$ Respeitados os limites constitucionais, podem ser estabelecidas normas e restrições para a utilização de uma propriedade privada localizada em uma Área de Proteção Ambiental. 
§ 30 As condições para a realização de pesquisa científica e visitação pública nas áreas sob domínio público serão estabelecidas pelo órgão gestor da unidade.

$\S 40$ Nas áreas sob propriedade privada, cabe ao proprietário estabelecer as condições para pesquisa e visitação pelo público, observadas as exigências e restrições legais.

$\S 50$ A Área de Proteção Ambiental disporá de um Conselho presidido pelo órgão responsável por sua administração e constituído por representantes dos órgãos públicos, de organizações da sociedade civil e da população residente, conforme se dispuser no regulamento desta Lei (BRASIL, 2000).

Por sua vez a RESEX tem uma característica particular de ser uma área utilizada para subsistência de populações tradicionais, as atividades mais comuns são o extrativismo, agricultura familiar e a criação de animais

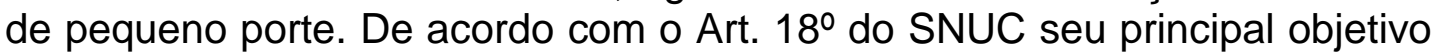
é proteger os meios de vida e a cultura da populações residente e assegurar o uso sustentável dos recursos naturais presentes na UC. Como características específicas do mesmo parágrafo temos as especificações que:

$\S 10$ A Reserva Extrativista é de domínio público, com uso concedido às populações extrativistas tradicionais conforme o disposto no art. 23 desta Lei e em regulamentação específica, sendo que as áreas particulares incluídas em seus limites devem ser desapropriadas, de acordo com o que dispõe a lei.

§ 20 A Reserva Extrativista será gerida por um Conselho Deliberativo, presidido pelo órgão responsável por sua administração e constituído por representantes de órgãos públicos, de organizações da sociedade civil e das populações tradicionais residentes na área, conforme se dispuser em regulamento e no ato de criação da unidade.

§ 3o A visitação pública é permitida, desde que compatível com os interesses locais e de acordo com o disposto no Plano de Manejo da área.

$\S 40$ A pesquisa científica é permitida e incentivada, sujeitando-se à prévia autorização do órgão responsável pela administração da unidade, às condições e restrições por este estabelecidas e às normas previstas em regulamento.

$\S 50$ O Plano de Manejo da unidade será aprovado pelo seu Conselho Deliberativo.

$\S 60$ São proibidas a exploração de recursos minerais e a caça amadorística ou profissional.

§ 70 A exploração comercial de recursos madeireiros só será admitida em bases sustentáveis e em situações especiais e complementares às demais atividades desenvolvidas na Reserva Extrativista, conforme 0 disposto em regulamento e no Plano de Manejo da unidade (Brasil, 2000).

Dessa forma entende-se que a criação das UCs propicia instrumentos legais, políticas públicas e conservação para a biodiversidade brasileira e o ecoturismo nas UCs oportuniza através do envolvimento com a comunidade residente, alternativas econômicas e conservação dos recursos naturais. 


\section{Considerações sobre o conhecimento local}

Os conhecimentos ecológicos tradicionais vêm sendo adotados por diversas áreas do conhecimento na busca de novas abordagens (Leite, 2010). De acordo com Moreira (2007, p.36) "o conhecimento tradicional é a forma mais antiga de produção de teorias, experiências, regras e conceitos, isto é, a mais ancestral forma de produzir ciência". Para identificar as comunidades tradicionais ele destaca que:

O que faz um grupo social ser identificado como tradicional não é a localidade onde se encontra, ele pode estar em uma unidade de conservação, terra indígena, terra quilombola, à beira de um rio da Amazônia, num centro urbano, numa feira, nas casas afro-religosas, nos assentamentos da reforma agrária, enfim, não é o local que define quem elas são, mas sim seu modo de vida e as suas formas de estreitar relações com a diversidade biológica, em função de uma dependência que não precisa ser apenas com fins de subsistência, pode ser também material, econômica, cultural, religiosa, espiritual etc. (MOREIRA, 2007, p.36).

Diegues (1996, p.75) afirma que Etnociência é a "parte da linguística que estuda o conhecimento de diferentes sociedades sobre os processos naturais, buscando entender a lógica subjacente ao conhecimento humano sobre a natureza, as taxonomias e classificações totais". Um tema interdisciplinar e transdisciplinar como a conservação ambiental e o ecoturismo podem se utilizar da Etnobiologia como forma de ampliar suas pesquisas.

Dentro da Etnobiologia existem vários campos podem ser definidos, partindo da visão compartimentada da ciência sobre o mundo natural, tais como a Etnozoologia, Etnobotânica, Etnoecologia, e assim por diante. Dessa forma, Toledo (1992) apud Sousa (2010) entende Etnobiologia como um "campo interdisciplinar em que se trabalha com as interações entre os seres humanos e os componentes vegetais, animais e microbiológicos do seu ambiente", a autora se utiliza do seguinte autor para referenciar a importância do Etnoconhecimento:

\footnotetext{
Lévi-Strauss (1962) destaca a importância desse conhecimento, ao afirmar a existência da elaboração de técnicas muitas vezes complexas, existindo nesses grupos humanos, uma atitude científica, uma curiosidade e alerta, uma vontade de conhecer pelo prazer de conhecer, pois apenas uma fração das observações e experiências poderia fornecer resultados práticos e imediatamente utilizáveis. Com relação à diferença entre o conhecimento científico e o tradicional, o autor afirma que são dois modos diferentes de pensamento científico, não em função de estágios desiguais de desenvolvimento do espírito humano, mas dois níveis estratégicos em que a natureza se deixa abordar pelo entendimento científico (SOUSA, 2010, p.18)
} 
Existe assim, uma relação entre $o$ etnoconhecimento $e$ as contribuições para a conservação dos recursos naturais, porém ainda existem desafios no entendimento e na metodologia aplicada para melhor utilização desse conhecimento, principalmente no turismo, pois é preciso valorizar um pouco mais o conhecimento local nessa área.

\section{Procedimentos metodológicos}

A área da pesquisa é conhecida por Praia da Barrinha e não possui muitas informações a seu respeito. Sabe-se que a praia está situada na Ilha das Canárias no município de Araioses no estado do Maranhão. Essa região fica nos limites entre os estados do Piauí e Maranhão.

A Ilha das Canárias é a "segunda maior do Delta, com 5 povoados (Canárias, Passarinho, Caiçara, Torto e Morro do Meio) e aproximadamente 3.000 habitantes, que vivem em sua maioria basicamente da pesca, da cata do caranguejo e da agricultura em pequena escala" (MATTOS, 2008, p.5).

A área está também dentro da região do Delta do Rio Parnaíba. De acordo com as pesquisas de Guzzi (2012):

O Delta do Rio Parnaíba é considerado o terceiro maior do mundo e o único encontrado no Continente Americano a desaguar diretamente no oceano, possui uma ampla área de cobertura com cerca de $2.750 \mathrm{Km} 2$, e é caracterizado como um complexo mosaico de ecossistemas entrecortados por baías e estuários. Situado entre os Estados do Piauí e Maranhão, caracteriza-se como uma região fluvio-marinha bastante dinâmica formada pela tensão ecológica entre as formações de Cerrado, Caatinga e Sistemas marinhos. Devido à sua alta produtividade primária é considerado como um santuário reprodutivo para inúmeras espécies migratórias (GUZZI, 2012, p3).

O Delta do Parnaíba é formado por cinco barras (Igaraçú, Canárias, Cajú, Carrapato ou Melancieira e Tutóia), a partir do rio Parnaíba, divisor natural dos Estados do Piauí e Maranhão é composto por mais de 75 ilhas, classificadas como ilhas de aluvião, que se formam em águas calmas (SAVAGET, 2002 apud MATTOS, 2008).

A Praia da Barrinha está também em uma área onde encontra-se duas UCs sobrepostas, são elas, A Área de Proteção Ambiental Delta do Parnaíba foi criada em 1996, compreende um perímetro de 460.812 metros e uma área de aproximadamente 313.800 hectares, abrangendo os municípios de Luís Corrêa, Ilha Grande e Parnaíba, no estado do Piauí; Araioses e Tutóia, no estado Maranhão; Chaval e Barroquinha, no estado do Ceará, além de águas jurisdicionais e a Reserva Extrativista Marinha do Delta do Parnaíba, criada em 2000, composta de algumas ilhas do delta compreende os municípios de Ilha Grande (PI) e Araioses e Água Doce (MA) e abrange uma área de aproximadamente 275,6 quilômetros quadrados (ZEE, 2002 apud MATTOS, 2008). Em resumo, a Praia da Barrinha é banhada pelo Oceano Atlântico, está localizada na porção extremo Oeste da 
Ilhas das Canárias, na Barra do Caju, Dentro de duas Unidades de Conservação.

\section{Pesquisa etnoecológica}

A pesquisa se utiliza das técnicas da Etnoecologia, foi realizada com moradores das diferentes comunidades pertencentes aos municípios de Araioses MA e Ilha Grande PI, que visitam a Praia da Barrinha com certo grau de frequência, não observando preferência de categorias de trabalho/ocupação e faixa etária, o objetivo foi encontrar autóctones que informassem aspectos sobre a praia que indicassem o desenvolvimento do ecoturismo, buscando informações de possíveis atrativos ecológicos.

Para definição de Amostra foi utilizada o método conhecido como Bola de Neve (snowball sampling), esse método consiste em interrogar um conjunto de atores (conhecedores autóctones) para coletar suas informações, assim "este método é caracterizado por ser um método rápido de coleta se a pesquisa for iniciada a partir dos elementos mais populares da rede" (LEITE, 2010, p. 55).

Baldin e Munhoz (2011) esclarecem o uso desse método de acordo com suas práticas adotadas em seus estudos sobre Educação Ambiental:

(...) os participantes iniciais de um estudo indicam novos participantes que por sua vez indicam novos participantes e assim sucessivamente, até que seja alcançado o objetivo proposto (o "ponto de saturação"). O "ponto de saturação" é atingido quando os novos entrevistados passam a repetir os conteúdos já obtidos em entrevistas anteriores, sem acrescentar novas informações relevantes à pesquisa. (WHA, 1994 apud BALDIN; MUNHOZ, 2011 p. 332).

Portanto, a snowball ("Bola de Neve") gera uma espécie de rede onde, o primeiro participante contatado na aplicação da pesquisa é a "semente", que deve ser escolhida pelo seu conhecimento da localidade, dele se inicia a cadeia de indicações que serão os "filhos" das "sementes". Para gerar uma boa quantidade na amostra a "semente" deve preferencialmente, exercer certa liderança no espaço a ser estudado, conhecer muitos membros da localidade e que esses sejam de diversificados ramos de formação e atuação (BALDIN; MUNHOZ, 2011).

Para Dewes (2013), o método bola de neve é muito útil no caso de populações raras ou desconhecidas, onde os membros destas populações não podem ser todos identificados previamente e são mais difíceis de encontrar ou contatar, essas populações, sendo desconhecidas não possuem uma lista de membros e construir uma é tarefa difícil ou impraticável, incluindo um alto custo financeiro e de tempo para aplicação. Através do esclarecimento de Dewes justificou a motivação da escolha desta metodologia para um estudo da Praia da Barrinha, pois a praia tem as mesmas características descritas pelo autor, que também apresenta que "se o objetivo do estudo é exploratório, qualitativo e descritivo, a amostragem 
em bola de neve oferece claramente vantagem em obter informações de populações escondidas ou difíceis de encontrar que seriam, de outro modo, muito difíceis de coletar" (HENDRICKS; BLANKEN, 1992 apud DEWES, 2013, p.12).

\section{Pesquisa de campo}

O estudo tem em geral caráter qualitativa e exploratória e se iniciou com pesquisa bibliográfica para levantamento de informações sobre a área de estudo, constatou-se a falta de informações sobre a praia. A pesquisa de campo foi realizada durante as atividades do Projeto Biomade, foram realizadas duas visitas ao local durante os monitoramentos da área onde despertaram inicialmente a ideia da pesquisa, uma terceira visita foi realizada dia 02 de janeiro de 2015 para aplicação das etapas metodológicas nas comunidades necessárias.

Utilizou-se como primeiro instrumento de coleta a entrevista estruturada, contendo questões fechadas e questões abertas, que seguiam um roteiro pré-estabelecido e direcionavam as respostas para as informações que a pesquisa pretende atingir, as respostas foram gravadas e transcritas e utilizadas na análise dos dados.

De acordo com as normas da entrevista estruturada, o entrevistador deve seguir um roteiro previamente estabelecido; as perguntas feitas são predeterminadas de acordo com um formulário (APÊNDICE - A) elaborado e é efetuado de preferência com pessoas selecionadas de acordo com um plano, no caso deste estudo trata-se da definição da amostragem. Essa padronização de perguntas permite que as respostas sejam comparadas, nesse modelo, o pesquisador não deve adaptar, alterar ou reordenar as perguntas de acordo com a situação (MARCONI; LAKATOS, 2006)

As entrevistas foram realizadas entre os meses de dezembro de 2014 e Janeiro de 2015, tendo uma duração média de 20 minutos. Antes de Início das entrevistas os participantes foram esclarecidos sobre os objetivos da pesquisa e ao final assinaram o Termo de Consentimento Livre e Esclarecido (APÊNDICE - B).

A pesquisa de campo também configurou uma etapa importante de coleta de dados, pois nela foi possível observar os atrativos e realizar os registros fotográficos para a análise de dados.

De acordo com a metodologia aplicada (Bola de Neve), o entrevistador não é capaz de escolher os sujeitos da pesquisa, porém, para que se alcancem os objetivos propostos é preciso que o entrevistado frequente a praia da barrinha com pelo menos frequência mensal e pertençam as comunidades próximas ao local pertencentes principalmente aos municípios de Araioses (MA) e Ilha.

A primeira etapa da aplicação da metodologia foi a definição dos entrevistados através do método de amostragem bola de neve, onde foi definido os sujeitos da pesquisa e ao mesmo tempo aplicado as entrevistas.

Após os resultados foi realizado a primeira sintetização dos dados, fazendo um levantamento de informações básicas sobre a praia e fazendo 
um levantamento sobre os principais atrativos. O levantamento dos possíveis atrativos subsidiou uma visita de campo quando se realizou os registros fotográficos (ou não) dos locais indicados.

A última etapa do processo metodológico é a tabulação e análise dos dados para atingir os três resultados principais do estudo, são eles: um diagnóstico preliminar da Praia da Barrinha, um inventário de principais atrativos e a partir disso a sugestão de melhores práticas para o local.

\section{Resultados e discussão}

Através da aplicação da metodologia de amostragem bola de neve, chegou-se ao número de 16 entrevistados, porém 10 entrevistas foram selecionadas por serem pontos de saturação no método snowball, ou seja, aqueles que eram indicados (citados) mais vezes, assim a utilização do método, possibilitou a escolha do informante de maior conhecimento sobre a praia, por coincidência, o mais citado foi o Informante $A$, possivelmente que pela frequência de visitas a Praia da Barrinha e pela popularidade na região.

A entrevista voltada para atrativos turísticos também levou os entrevistados a indicarem o Informante $A$, que é condutor de turismo no Delta do Parnaíba a mais de 20 anos, prestando serviços pontuais para várias empresas, turistas ou moradores da região, por esse motivo, havia sido escolhido como semente da pesquisa anteriormente.

Todos os entrevistados citados foram do gênero masculino, a faixa etária apresenta que $70 \%$ estão entre 32 e 53 anos de idade, $90 \%$ deles são casados e pertencem principalmente a comunidade das Canárias (MA), com $50 \%$, depois Torto (MA) e Tatus (PI) com 20\% e um entrevistado da llha Grande.

De acordo com os dados coletados, as pessoas mais indicadas pelo método a falar sobre a Praia da barrinha são moradores da comunidade de canárias que realizam atividade pesqueira na área da Praia da Barrinha, pois $70 \%$ são pescadores e 30\% condutores de turismo e dos 7 pescadores 5 são da comunidade de Canárias. Elaborando uma análise mais precisa, essas características podem mostrar que os moradores das comunidades de entorno da praia, sempre a buscam como fonte de geração de renda, seja para atividades de pesca ou atividades de turismo, sempre ligada aos recursos naturais.

A pesquisa procurou saber a frequência média em que os pescadores visitam a praia, buscando investigar a quantidade de visitas realizadas pelos entrevistados, onde $60 \%$ dos entrevistados com visitas a praia apenas mensalmente, mais uma vez indicando a atividade de pesca, pois é realizada em função da maré, essa visita à praia dura entre cinco e sete dias, outros $30 \%$ afirmou frequentar a praia em média uma vez por semana e apenas um entrevistado que corresponde a $10 \%$ dos entrevistados afirmou visitar a praia apenas nos meses de julho e agosto, durante a entrevista ele revelou que "levo turistas que praticam Kitesurf desde a Ilha dos Poudros até a Praia da Barrinha” (INFORMANTE J, 2015). 
Um dos questionamentos era se o entrevistado considera a Praia da Barrinha como um atrativo turístico do Delta do Parnaíba, nove entrevistados que correspondem a 90\% responderam que sim e apenas um, que representa 10\%, respondeu que não, para o Informante I (2015), "a praia da barrinha não tem nada para o turista ver" alegando que os atrativos são insuficientes para justificar a distância, nesse caso a maioria acredita que o local já é um atrativo.

Nove entrevistados responderam que a Praia da Barrinha era sim um atrativo turístico porque: "lá o pôr do sol mais bonito do Delta, tem muitos bichos, principalmente aves, também tem os botos e o passei dá pra ver muita coisa" (INFORMANTE A, 2015); "A praia é limpa e boa" ( INFORMANTE B, 2015); "por causa da praia" (INFORMANTE C, 2015); "lá tem muita planta e animais que são bonitos, os turistas também iam gostar de ver os pescadores pescando" (INFORMANTE D, 2015); "por que lá é muito lindo, ainda não tem gente morando, fica deserto, tem muitas aves também" (INFORMANTE E, 2015); "porque tem os morros, as vezes dá pra ver Guarás de lá, tem muitas garças também, lugar tranquilo, mas não dá pra ficar muito tempo lá porque não tem nada, nem banheiro, restaurante, aí o pessoal vai lá só de passagem" (INFORMANTE F, 2015); "a praia é bonita e tem muitos bichos, tem marés que os botos saem pra pescar lá perto" (INFORMANTE G, 2015); "a praia é bonita, os turistas vão lá para ver o pôr do sol, tem boto lá mas tem as marés que ele sai, é mais difícil" (INFORMANTE H, 2015); "lá é bonito" (INFORMANTE I, 2015).

A análise das respostas coletadas sugere uma lista de atrativos que incluem a paisagem (elementos que sugerem isso: pôr do Sol, beleza da praia, plantas), a atividade de pesca e os animais. Um elemento importante é identificado indiretamente nessa pergunta, é que o turismo realizado nela é do tipo excursionista, quando ele menciona que a praia não possui moradores, portanto, não tem infraestrutura para manter o turista no local por muito tempo.

Todos os informantes afirmaram que é possível visualizar vários animais na praia. Como um consenso, os pescadores disseram que não existe uma hora exata para observar os animais, "até os guarás mudaram de lugar e hoje estamos dispensando passeios porque não conseguimos mais ver a revoada dos guarás" (Informante I, 2015), "o melhor momento para avistar aves, cobras e jacarés é no fim da tarde ou de acordo com a maré" (Informante B, 2015), "aquela região é rica em ninhos de aves, se passar perto do mangue dá pra ver muitos" (Informante A, 2015).

Foram citados uma lista de animais selvagens que podem ser bem atrativos, os mais citados como animais selvagens que podem ser visualizados pelos turistas foram: Muitas Aves (principalmente guará e garças), o Boto-Cinza, cobras, raposas. De acordo com o Informante $F$ (2015) "no caminho até chegar lá dá pra ver muitos outros animais", nesse contexto, também foram citados (macacos, jacaré, capivara e iguana).

Todos eles também afirmaram que a praia da Barrinha é uma praia pouco frequentada onde a maioria são pescadores e uma minoria são turistas. Por fim, as visitas de campo realizaram um levantamento de 
quantos desses atrativos mencionados foram encontrados para inventário preliminar de atrativos na Praia.

\section{Considerações de diagnóstico: Praia da Barrinha}

De acordo com as análises das entrevistas realizadas e da pesquisa de campo, constatou-se que a Praia da Barrinha possui características ambientais muito peculiares, a praia não possui ocupação humana e a comunidade mais próxima chama-se Morro do Meio. É necessário percorrer aproximadamente $42 \mathrm{~km}$ de lancha ou embarcações de pequeno porte para chegar ao local pela dificuldade de acesso, os igarapés que facilitam o traslado dependem de maré para permitir fluxo por meio fluvial, considerando o ponto de partida o Porto dos Tatus, ponto de acesso mais fácil para a Ilha das Canárias.

A área de estudo localiza-se dentro da APA Delta do Parnaíba e da Resex Marinha simultaneamente, o que permite seu uso sustentável, porém esse uso e ocupação devem ser regulamentados pelos planos de manejo da área que está em fase de elaboração. Segundo frequentadores da praia o turismo já ocorre no local, porém de formas esporádicas.

Alguns aspectos turísticos foram observados, apesar da área possuir muitos atrativos ecológicos tem pouca visitação, as pessoas que frequentam a praia são na maioria pescadores provenientes da comunidade de Canárias que passam entre 5 e 7 dias acampados em ranchos construídos na praia com madeira e palha.

Pelo depoimento dos autóctones acredita-se que a atividade turística na praia não é maior por que os animais e paisagens formam uma dinâmica muito grande, não permitindo sua visualização sempre, a distância e o difícil acesso também são fatores dificultadores para o ecoturismo nessa região.

Constatou-se que o pouco tipo de turismo realizado se trata na verdade do excursionismo, pois o visitante não permanece mais de 24 horas no local pela inexistência de qualquer infraestrutura de apoio.

Porém, a Praia da Barrinha está localizada numa área de estuário, local que serve para alimentação, descanso de espécies migratórias e refúgio de animais inclusive em extinção, além das oportunidades ecológicas a região apresenta grande potencial para turismo cultural, de acordo com os pescadores e guias que frequentam a praia acompanhar a atividade de pesca já é um atrativo turístico por si.

As paisagens com manguezais e rios escondem riquezas naturais muito importantes para as populações, essa riqueza em biodiversidade oportuniza diversas atividades de ecoturismo, porém despertam uma série de preocupações para o desenvolvimento do ecoturismo nessa área.

O Inventário preliminar foi realizado através do registro fotográficos de elementos que podem ser atrativos para justificar o desenvolvimento do ecoturismo na praia da Barrinha. Os registros foram realizados durante pesquisa de campo junto ao ITD, como resultados foram encontrados 
praticamente todos os atrativos citados pelos entrevistados. Como informado pelos participantes da pesquisa, foram encontrados elementos da fauna e flora suficientes para justificar a procura de ecoturistas para vivenciar o local.

A realização do diagnóstico e breve inventário, possibilitou constatar que a região estudada apresentou muitas possibilidades para 0 desenvolvimento do ecoturismo, porém, esse estudo exploratório inicial sugere aprofundamento nas investigações, a praia da Barrinha apresentou características de uma área sensível, a presença de animais ameaçados de extinção como o Boto-cinza funcionam como mais um indício de região ainda conservada, esses animais acabam se tornando indicadores ambientais, ou seja, se existem espécies frágeis em um ambiente ele pode ser um ambiente ainda saudável. Segundo Molina:

As praias, manguezais, sistemas lacustres, arrecifes, rios e estuários são exemplos de ecossistemas valiosos para o turismo, e, muitas vezes, não são adequadamente avaliados no quadro dos planos e programas de desenvolvimento turístico (MOLINA, 2001, p.57).

Sugere-se para essa região mais estudos que possam basear planejamentos de uso, ocupação e manejo da área, ou atividades educacionais e científicas, afinal, embora distante do porto dos Tatus o próprio percurso revela muitas possibilidades.Nesse sentido, através de observações e registros do Projeto Biomade, como a canoagem, traking e camping, observação de aves, ou outras atividades que não exijam imediatos investimentos e infraestrutura.

\section{Considerações Finais}

Por meio do presente estudo, identificou-se uma área pouco frequentada, mas com potencialidades ecológicas suficientes para justificar a atividade turística sustentável. Foi elaborado um breve diagnóstico a partir da observação da fala dos autóctones através do etnoconhecimento, em resumo, o diagnóstico revelou a necessidade de pesquisas bem mais apuradas na região devido a poucas produções científica ou a existência de pesquisas superficiais.

Assim, a Praia da Barrinha apresentou-se como um local com grande potencial ecoturístico, porém, com grandes desafios de proteção, as áreas de berçário, alimentação, refúgio e descanso de muitos animais.

Recomenda-se para Planejamento da área um estudo turístico aprofundado. Como critérios sugerem-se estabelecimentos de limites ecológicos, conservação dos recursos, investimento em tecnologias, estudo de capacidade de carga e monitoramento ambiental em áreas prioritárias. Devem existir também mais atividades para preparar o turista como informações antes da visita, a tendência é que os novos turistas aos poucos se conscientizem num grau de abandonar velhos costumes e consumismos, assumindo um novo papel frente à conservação ambiental. 
Portanto, o planejamento do ecoturismo deve sustentar a natureza explorada para garantir a continuidade do turismo nesse local, por meio do monitoramento de capacidade de carga e minimização dos impactos, deve inserir a comunidade para enriquecer seus roteiros e deve entender que o ecoturista não exige equipamentos sofisticados, mas não abre mão da higiene e conforto.

Por fim, espera-se que este trabalho, estimule o cuidado com o ambiente, o senso de planejamento sustentável e a criatividade dada em torno do ecoturismo buscando o despertar do Delta do Rio Parnaíba para novas possibilidades de uso e conservação do meio ambiente, com maior diversidade em suas atividades e envolvimento das comunidades tradicionais das ilhas do Delta.

\section{Referências bibliográficas}

BALDIN, N; MUNHOZ, E. M. B. Snowball (Bola de Neve): Uma técnica metodológica para a pesquisa em educação ambiental comunitária. $X$ Congresso nacional de Educação - EDUCERE, Curitiba, 2011.

BNDES. Turismo ecológico: uma atividade sustentável. Disponível em: $<$ http://www.bndespar.com.br/SiteBNDES/export/sites/default/bndes pt/Gale rias/Arquivos/conhecimento/setorial/get4is10.pdf> Acesso em: 22 de Dezembro de 2014.

BRASIL, Ministério do Turismo. Segmentação do Turismo: Marcos Conceituais. Brasília: Ministério do Turismo, 2006. Disponível em: $<$ http://www.turismo.gov.br/export/sites/default/turismo/o ministerio/publicac oes/downloads publicacoes/Marcos Conceituais.pdf> Acesso: 03 de Janeiro 2015.

BRASIL, Ministério do Turismo. Ecoturismo: Orientações Básicas. Brasília: Ministério do Turismo, 2010.

BRASIL, Ministério do Meio Ambiente. Ecoturismo: Visitar para conservar e desenvolver a Amazônia, Brasília:MMA/SCA/PROECOTUR, 2002.

CORIOLANO, L.N.M.T. Turismo e Meio Ambiente: interfaces e Perspectivas. In: CORIOLANO, L.N.M.T; VASCONCELOS, F.P. (Org.). O turismo e a relação Sociedade-Natureza: realidades, conflitos e resistências. Fortaleza: EdUECE, 2007.

CORREIA, C.B.S. Evolução do Ecoturismo no Brasil: de 1993 a 2003. Monografia (Especialização em Ecoturismo). Centro de Excelência em Turismo da Universidade de Brasília, 2003.

DEWES, J.O. Amostragem em Bola de Neve e Respondent-Driven Sampling: uma descrição dos métodos. 52 p. Monografia (Monografia Bacharel em Estatística.) Instituto de Matemática - Departamento de Estatística, Universidade Federal do Rio Grande do Sul (UFRGS), Porto Alegre, 2013.

DIEGUES, A.C. O mito moderno da natureza intocada. São Paulo: IIUCITEC, 1996. 
GUZZI, A. Biodiversidade do Delta do Parnaíba: Litoral piauiense. Parnaíba: EDUFPU, 2012.

MOLINA, S. Turismo e Ecologia. Baurú, São Paulo: EDUSC, 2001.

OMT. Disponível em: <http://media.unwto.org/press-release/2014-1218/international-tourism-track-end-2014-record-numbers > Acesso em: 03 de Janeiro 2015.

SWARBROOKE, John. Turismo Sustentável: Turismo Cultural, Ecoturismo e Ética. Vol.5. São Paulo: Aleph, 2000.

SÃO PAULO. SECRETARIA DO MEIO AMBIENTE. Ecoturismo. São Paulo: SMA, 2011.

WEARING, S.; NEIL, J. Ecoturismo: impactos, potencialidades e possibilidades. Barueri: Manoele, 2001.

Mayara Maia Ibiapina: Universidade Federal do Piauí, Teresina, PI, Brasil.

E-Mail: myaramaia@hotmail.com

Link para o currículo Lattes: http://lattes.cnpq.br/4035485473219885

Data de submissão: 30 de agosto de 2016

Data de recebimento de correções: 10 de setembro de 2016

Data do aceite: 16 de setembro de 2016

Avaliado anonimamente 